\title{
The concealed ethnobotanical rituals associated with biodiversity conservation in shinasha people, bullen dstrict, western ethiopia
}

\begin{abstract}
The establishment of ethnobotanical reserves or medicinal plant nurseries, dedicated to the growth of indigenous plants under natural conditions, has been seen by many conservationists as a necessary step towards protecting the rich biodiversity of Ethiopia. However, the establishment of such reserves amongst conservative rural communities has had little success to date. The paper provides an outline of perceived obstacles encountered by conservative traditional healers in the acceptance of medicinal plant domestication and knowledge transfer. Workers aiming to erect such nurseries in conservative areas must be particularly sensitive to gender issues as well as to traditional beliefs relating to fortune and misfortune. I argue that traditional belief systems need to be skillfully integrated with commercial practice in order to ensure the successful establishment of nurseries in these areas.
\end{abstract}

Keywords: biodiversity, ethnobotanical, knowledge transfer, medicinal plants, traditional healer
Volume 2 Issue 6 - 2018

\author{
Dereje Mosissa \\ Ethiopian Biodiversity Institute Assosa Biodiversity Center, \\ Ethiopia
}

\begin{abstract}
Correspondence: Dereje Mosissa, Ethiopian Biodiversity Institute Assosa Biodiversity Center, Forest and rangeland caseteam,Assosa, Ethiopia, Email deramant5964@gmail.com
\end{abstract}

Received: October 29, 2018 | Published: November 16,2018

\section{Introduction}

Recent years have seen a burgeoning interest in the documentation and utilization of indigenous knowledge systems in programmers relating to the conservation of the rich biodiversity of Ethiopia. A result of this approach has been the realization that an expanding population, together with the resiliency of traditional healing techniques amongst local communities, has placed severe pressure on flora used for medicinal purposes. ${ }^{1}$ The establishment of ethnobotanical reserves dedicated to the growth of indigenous medicinal plants for traditional utilization, has been seen by many as a necessary step towards solving this problem. Such nurseries have already been established privately at Ekontie, Dora Jala, and Mata Kebeles of Bullen district with many others being planned for the near future in the same province. Such objectives were often initiated by Ethiopian Biodiversity Institute to reduce pressure on biodiversity and secure the resource base by promoting a change from gathering to growing medicinal plants, by encouraging sharing of propagation material between growers in the form of seeds, seedlings, cuttings and stock plants. Wild specimens of vulnerable species are thus protected from overexploitation and agricultural land expansion.

One of the most significant target groups of potential growers were the traditional healers of the shinasha people remotely living in west of Ethiopia. The idea therefore is not only for traditional healers to harvest medicinal plants at these nurseries, but also to cultivate them in their own backyards. Traditional healers would also benefit from programmes from other areas of Ethiopia such as Zegie, Bahir Dar and Sonka, Assosa by developing business organisational capabilities, including finance and committee skills. Although programmes at Sonks Kebele have generated interest amongst urban- or peri-urbanbased traditional healers, most of these use ethnobotanical reserves only as harvesting locales. The vast majority of them do not cultivate their own medicinal plants. In other rural areas, of the region the establishment of commercial community nurseries has been a complete failure. Very few traditional healers have attempted to establish their own backyard nurseries, and these with mixed results.
Others, although initially interested in the concept, have expressed reservations about the long term success of these enterprises, in terms of the time and labor required to set up a functioning nursery. However, investigation of more conservative rural-based healers indicates that their reluctance to establish specialized nurseries stems from their perception that commercial nurserymen are ignorant about African traditions relating to medicinal plants.

In this paper I provide an outline of some of the more obvious ideological barriers encountered by conservative traditional healers to their acceptance of medicinal plant domestication. It is imperative that these perceptions be integrated with the establishment and running of ethnobotanical reserves to make the reserves acceptable to a conservative population. Most of my research was conducted amongst members of the traditional healers from Shinasha community which is situated at Bullen district. Some traditional healers at Sonka kebele frequently visit the commercial nurseries and so are familiar with the concept of cultivating medicinal plants. In addition, Mender 49 is one of the few areas in the district where a backyard nursery has been successfully established. The presence of many traditional healers in the study area, most of whom belonging to the Shinasha community, made it possible to interview the skeptics, as well as the only individuals to establish a medicinal plant nursery.

\section{A question of gender}

Traditional healers amongst Shinashigna speakers in Metekel Zone can be subdivided into three somewhat overlapping categories. However, healers interviewed indicated that only one category, namely diviners (Shetetsonè), would be completely comfortable with establishing their own backyard nurseries. I must indicate, however, that the same situation does not necessarily apply to the urban setting, where social and ideological change has been more dramatic. Here, a variety of traditional healers and other individuals may find the concept of specialized plant nurseries attractive and traditional herbalists (Shetetsonè) have also been known to grow medicinal plants. In fact, a visible indication that belief systems relating to 
medicinal plants have become more 'open' in the urban setting can be seen in the increase in female gatherers and sellers of medicinal plants, ${ }^{1}$ many of whom may be menstruating without any apparent taboo attached to this state of impurity (see below). This is a situation which would be totally unacceptable in conservative rural areas. Before the rural situation can be assessed, however, a summary of the various categories of traditional healers is pertinent.

The seemingly most obvious candidate for owning a backyard nursery would be the herbalist (Shetetsonè). The Shetetsonè is a master of medicine and has knowledge of a vast array of plants, roots, and other substances such as animal products used as spiritual ceremony. A prospective Shetetsonè who decides to take up this lucrative career, apprentices himself to an established herbalist. Training may take several months to a few years to complete, depending on the individual concerned. Throughout the province, herbalists are almost exclusively male; the idea that females may act as herbalists is socially frowned upon. As Berglund ${ }^{2}$ remarks: In the patrilineal and polygynous society of the Zulu, a woman who shows explicit interest in imithi (and is not a diviner) runs the immediate risk of being suspected of practicing sorcery or witchcraft (women often being associated with witchcraft). The herbalist's wanderings and scouring in search of medicines and contacts with strangers who seek medicines, is also in keeping with the social behavior of men rather than of women.

Although herbalists, especially those who are urban-based, are most certainly interested in obtaining medicinal plants from nurseries, few, if any, show any initiative to start up their own backyard operations. The reason for this peculiar state of affairs is also genderbased. Traditional Nguni society is strongly patriarchal and division of labor along gender lines is highly emphasised. Whereas livestock and its various implications are associated with men, ${ }^{3}$ cultivation of fields and the growing of cultigens is typically a woman's affair. Given this scheme of things it is not difficult to understand why herbalist, who is predominantly male, would feel uncomfortable cultivating plants.

Interestingly, the majority of traditional healers who have cultivated their own medicinal plants' appear to be male diviners or herbalists who have also been initiated as diviners. Again this tendency can be explained with reference to gender. In contrast to herbalists the diviner is almost exclusively female. Various writers have noted that this strong gender bias amongst Nguni diviners may relate to social factors. ${ }^{4}$ The role of a diviner allows a strong-willed woman to engage in a lucrative profession which carries great social prestige, and contrasts with the generally low status of women in traditional society. It also allows men who, by temperament, do not fit into the Nguni masculine mould to opt for a more congenial role, in which their femininity may be recognised. ${ }^{4}$ Lee, ${ }^{5}$ for instance, observed that the few Zulu male diviners he knew were almost certainly homosexual and were usually young and unmarried at their initiation. Furthermore, male diviners are usually trained by female practitioners, and frequently adopt female dress, utilise space in the domestic unit in a way similar to women, and will often speak in high-pitched tones. However, given that women diviners, who may be menstruating, are perceived to be more at risk of suffering from ritual impurity or pollution (see below) than their male counterparts, it is not surprising that most diviners who have their own backyard nurseries are male. Whereas a herbalist is schooled in the manipulation of powers residing in material medica and relies solely on this for his knowledge, diviners relate their activities in divination and healing to the ancestors or shades. Unlike herbalists, diviners are called upon by the ancestors. This is manifested by the onset of a series of persistent symptoms, referred to as marra, which may include spells of dizziness, nervousness, troublesome dreams and periods of unconsciousness. Training may take two to three years and during this time the trainee will accompany her trainer on travels through the community and on expeditions to collect medicinal plants.

Although diviners have knowledge of medicinal plants, this knowledge is not as extensive as that of herbalists. Initiates are taught some herbal lore by their trainers. Typically, however, a diviner will be guided by the ancestors in a dream, as to which plants to seek for medicinal purposes. It is for precisely this reason that botanists and ecologists often avoid those who rely on dreams (i.e. diviners) when researching the ethnobotanical properties of plants. ${ }^{6}$ However, diviners are to a great extent bound by traditional views, whereas herbalists constantly experiment with new materia medica and mixtures of these.

The third category of traditional healer is that of prophets (dates enasha). Prophets are typically associated with the various independent church movements. ${ }^{7}$ Some are closely linked with diviners and claim to have similar metaphysical experiences and training. Although many dates enasha belong to traditional healer their healing work is for the most part based on prayer and sanctification with holy water and ash. Herbal remedies are of secondary or no importance and I exclude this category from the list of potential nursery owners.

To sum up: in terms of the conceptual framework set by traditional ideology, male diviners (shetetseka) and diviners who are also trained as herbalists, would be the most suitable candidates to accept the nursery concept. Where ideological change has been more severe, such as in urban contexts, herbalists will find it conceptually more acceptable to cultivate their own medicinal plants. However, it is not only the category of traditional healer which may influence the acceptance of medicinal plant nurseries in more conservative areas, but also systems of action relating to the collecting, planting and harvesting of medicinal plants. I now look at these in more detail.

\section{The nursery as liminal construct}

Traditional cosmology shares the conviction that material substances of many kinds, particularly the various species in vegetation, contain power (amandla). Because these plants are generally believed to be neutral they can be used either morally and legitimately, or to harm. ${ }^{2}$ Traditional healers interviewed agreed unanimously that medicinal plants growing in the wild, such as in natural woodlands, grasslands and along watercourses, will have more power than those cultivated in a nursery. In fact, the actual plant is often less important than the place in which it is found. It is especially those medicinal plants growing in indigenous forests which are believed to be the most potent. The potency of medicinal plants in a forest is said to be related to the age of the forests, which are believed to be ancient. In fact, it is said that they are so old that the Supreme Being (Datsè tsata or Iqaa) had a direct hand in the creation of them. In addition, it is believed that bark obtained from very old trees, such as those found in forests, is more potent than that obtained from young plants. That some the so called "gifted" clans of shinasha were buried in forests imbues these places with a special kind of sacredness. Such forests are traditionally avoided by secular people. Indigenous forests are therefore seen to be important places of power - a power which can be utilized for both positive and evil (anti-social) purposes. Forests, for instance, are not only utilized by traditional healers but also by witches and sorcerers. 
It is believed that the fearsome witch's familiar (awuu sháshá), a powerful eye), is secreted in forests, whilst many of the harmful plants used by sorcerers also abound in these localities.

Medicinal plants growing in the wild, especially those in inaccessible areas, are also seen to be potent, this because people's shadows have not fallen upon them. Raum, ${ }^{8}$ for instance, mentions the Shinasha tribe's belief that a person who allows his shadow to fall over that of another, thus blotting it out, causes the extinction of the life-essence of the person on whom the shadow falls. Similarly, conservative healers always strive to collect those medicinal plants which have not been exposed to a person's shadow, as it is believed that the plant will then not have lost all its medicinal and magical qualities. These ideas complement those belief systems in which water obtained from a crevice in a cave contains more healing properties [i.e.' living water'] ${ }^{2}$ than water from a tap, as no person could have jumped over the cave. Given these belief systems, it is therefore not surprising that traditional healers are quick to acknowledge that plants artificially cultivated in a nursery are unlikely to be as potent as those growing in the wild.

The aspiring backyard nursery entrepreneur, therefore, not only has to ensure that his cultivated plants retain their power, but conceptually also has to neutralise the wild plants when introducing them into the nursery. The spatial setting of the backyard nursery at the edge of the homestead, as practiced by aba Kebede, can be interpreted as an attempt to associate the wild medicinal plants (and by implication, nature) with the domestic and/or cultural sphere (Figure 1). As Elliot Kebede explained: 'not just any piece of land can be used, the ancestors must first be asked and then they will show a suitable area close to the homestead'. In a sense the medicinal plants must be introduced to the ancestors of the homestead and brought closer into the ancestor's domain to utilise their positive attributes more effectively. However, the nursery should not be too close to the homestead or people pointing with their index fingers at the plants may also damage them. Ideally, the backyard nursery must be situated somewhere on the margin of the healer's homestead; however, where precisely relative to other structures depends upon the healer's choice, in an area indicated by the ancestors. The backyard nursery, as the producer of healing plants, thus functions as a liminal construct ' betwixt and between' the natural and cultural worlds. It contains potent, and by implication, dangerous, plants such as are found in wild places well removed from the secure and socially benign domain offered by the homestead. However, the medicinal plants are ultimately utilized for aiding society and therefore serve as a bridge between the natural and cultural worlds; by planting them closer to the homestead of the healer they also take on cultural qualities and in a sense become domesticated.

\section{Collecting plants in the wild}

It is not only the spatial setting of the backyard nursery which serves to domesticate the wild medicinal plants, but also systems of action relating to the collecting and harvesting of these plants in the wild. Conservative healers maintain that traditional collecting practices of medicines need to be adhered to in order to maintain the potency of the plants and to appease the ancestors of the traditional healers. In fact, the ancestor cult which plays such a prominent part in African traditional cosmology is of equal importance in informing traditional healers, especially diviners, of their practices relating to medicinal plants. When it is considered that the Shinasha world viewer (Beqetsa or Tsilka) typically explains illness and misfortune as being caused by the ancestors and witches, then it is obvious that medicinal plants should form an integral part of this belief system. Typically misfortune sent by the ancestors is rectified through sacrifice, whilst that caused by witches and sorcerers is combated with awuu sháshá. However, the ancestors are also implicated in the use of medicinal plants. Berglund, for instance, quotes a diviner as saying: ' if the shades do not give power to medicines, they (the medicines) are useless (1976: 347).

It is also the ancestors who prescribe that some medicinal plants, such as wolii sheta (a mistletoe growing on phoenix) which are used to expel evil spirits, be collected only when the collector wears traditional clothing. Nowadays women wearing a traditional cotton skirt (borè fara) and male collectors going barefoot would suffice (Figure 1).

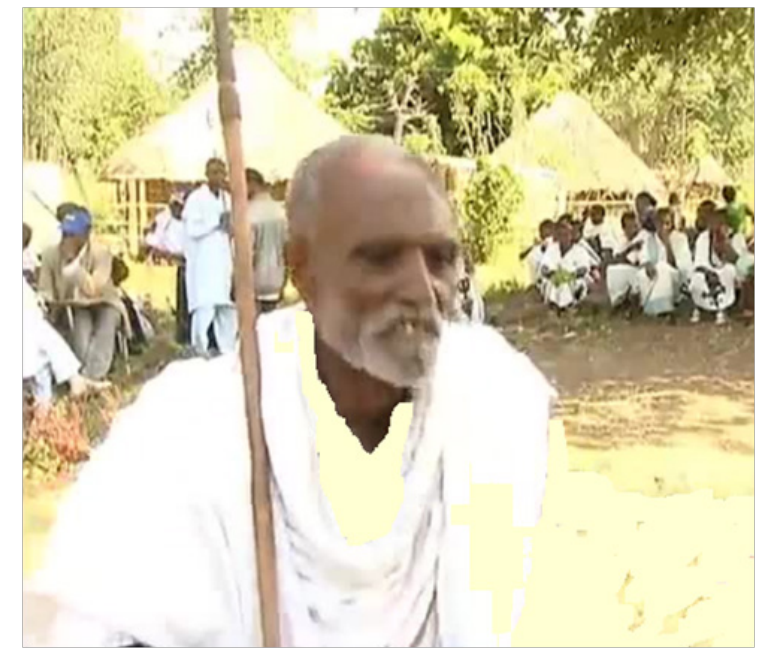

Figure 1 The herbalist (diviner) wearing a traditional cotton clothing.

As with plants already growing in a nursery the collector should never point with their index finger at those plants which he/she intends removing from the wild. The prohibition against pointing also refers to other objects, such as graveyards, hills, fields, and the rainbow on the sky, closely associated with the ancestors and/or the Supreme Being (Iqaa). In addition, pointing is illegitimately performed by evil-doers and a person pointing his finger at another was in the past thought to be a wizard. ${ }^{8}$

The collector should address the medicinal plants by their Shinasha names when removing them and asking their permission to do so. Ideally the collector should tell the plant what use will be made of it. In a sense the medicinal plants should be treated as if they are ancestors, as is also revealed in the custom of placing some money (mostly 2 Ethiopian birr) or butter in the hole left by the removed plant. This action will ensure that the collector 'takes the power' of the medicinal plant along. It is said that the butter, like money, is 'a lucky thing ', ensuring that the ancestors' iqoo (spirits) co-operate in maintaining the healing and magical qualities of the plants. Some traditional use the hands of their impaired son with bloodline or grown as gudifacha (Gutsè naá) to remove medicinal plants by placing a piece of their cloths on the spot where a plant has been removed, " to replace the power which has been removed back into the soil'. It is believed that hair contains spiritual power - the longer the hair the more power, hence the practice amongst some diviners to grow their hair as long as possible. However, there are also other customary practices which should be adhered to by any collector of medicinal plants. When collecting munna, (Tephrosia sp. a plant used for securing a lover) 
the collector must be naked. Other known medicinal plants maintain their power only when harvested at full moon, among these being the tokèri ataa (Osyridicarpos schimperianus or lasminum anguiare, to keep children sleeping) and barri atta (an unidentified species used by people in order to become 'invisible' during war or be confident to win the opponents). Bark removed from trees such as umnukani (Ocotea bullata), supposedly gains medicinal and magical qualities only after the wound on the scarred tree has healed. Because belief systems relating to medicinal plants form part of a larger worldview it is to be expected that they will also be duplicated in other spheres. For instance, when killing a porcupine (Tsalla) for medicinal purposes, the healer should always insert a white bead in the porcupine's mouth. The correct traditional procedure when killing a python (Darèwa, an animal closely associated with the ancestors) would be to sacrifice a black goat and to request the ancestors to restore the healing qualities of the python. The evidence therefore clearly suggests that the actual medicine and any potential chemical or biologically active constituents, is often less important than the place or conditions in which it is found. Unfortunately conservationists and other field workers are often unaware of these customary ' rules' and unknowingly introduce unsuitable plants to ethnobotanical reserves.

\section{Prohibitions and pollution at the medicinal plant nursery}

Once the nursery is established, certain customary prohibitions must be adhered to in order to maintain the potency of the plants. These include aspects already mentioned such as avoiding pointing, shadow casting, and stepping over the plants. In addition, nursery owners should also include medicinal plants such as tseraa (unidentified species) to combat the dangerous and malevolent powers of existing plants in the nursery. Medicinal plants whose power needs to be contained in this way include wollaa (Stangeria eriopus, used to ensure that a traditional healer has no customers), Foki munna (Stapelia gigantea, used to kill or harm opponents), and Barrohi sheta (Erianthemum dregi, used to make people smelly).

Traditional healers maintain that it is people's ignorance of aspects relating to pollution which can be the most damaging to plants growing in the nursery. Accordingly a person often experiences a particular dangerous state - often through no personal fault. These states all have strong negative aspects, must be removed as soon as possible, and may be thought of as states of pollution. ${ }^{4}$ Borè nono speaking communities have a well-developed conceptual system of pollution which is conceived of in terms of 'darkness' (talwa). According to Ngubane ${ }^{9}$ pollution among the other communities in Ethiopia is essentially a happening associated with ' birth ' on the one hand and 'death' on the other, and as such is viewed as a marginal state between life and death. Not only is talwa conceptualised as a mystical force which diminishes resistance to disease and creates conditions of misfortune, but it may also be contagious. It is therefore not surprising that people with talwa (including traditional healers) are prohibited from handling medicinal plants lest the plants lose their powers and properties. The types of pollution most frequently encountered by traditional healers include those associated with menstruating women, a woman who recently had given birth or had an abortion, a person who had sexual intercourse the day before, a person who attended a funeral, and men returning from battle (faction fighting or political violence).

In all these instances the people involved ideally must be barred from entering a nursery. Traditional healers, however, realize that this is not always possible as it is not necessarily known whether or not visitors to a nursery are polluted. Alternatively certain medicines must be used to protect the nursery against these possible influences. Perhaps the best known for these purpose is mochira (Cymbopogon citratus), is a domestic grass, which should be planned in front of the nursery entrance.

This medicine must also be ground and sprinkled every second day in and around the nursery, especially at the entrance path, to " remove the power from the shade (chish baziya) of an affected person'. When visitors are suspect they should also wash their hands with this medicine. This is in line with the general Shinasha herbalists perception of pollution as dirt which must be removed by washing actions. ${ }^{4}$ Per on assisting a nursery owner, especially those handling the medicinal plants, ideally should be very young (pre-adolescent) or old (post-menopause), or (purposefully castrated men) as it is generally believed that such persons are free from pollution.

\section{Conclusion}

Although the establishment of ethnobotanical reserves has become a high priority among those interested in protecting the biodiversity of Ethiopia, most of these initiatives are spear-headed by workers trained in the natural sciences, with little or no anthropological background. An understanding of traditional belief systems, however, is imperative when working with more conservative respondents. Whilst it is true that traditional belief system are fluid and certainly more 'open " in urban or peri-urban setting, customary avoidances and taboo associated with medicinal plants are still rigidly maintained in rural areas. For the nursery concept to be acceptable in more conservative settings, traditional belief systems must be skillfully integrated with commercial practice. Worker aiming to set up nurseries in conservative areas must be particularly sensitive to gender issues as well as customary beliefs, such as those associated with the ancestor cult and the pollution concept. In fact, a common perception amongst traditional healers is that those people from outside Africa who manage commercial nurseries (and medicinal plant shops) have little knowledge of African traditions and therefore unknowingly sell or distribute plants with no potency. It is only once a concise effort is made to familiarise workers with African customary beliefs, that conservative communities will be more agreeable to the nursery concept.

\section{Acknowledgements}

I would like to thank Tesfaye Awas $(\mathrm{PhD})$ for critical comments on earlier drafts of this paper. Thanks are also due to elders of the Shinsha community, especially Elliot Kebede, for their friendliness and co-operation during the fieldwork.

\section{Conflict of interest}

The authors declare that there is no conflict of interest regarding the publication of this article.

\section{References}

1. Cunningham AB. The resOllrce vallie of illdigenoLls plalls 10 rural people ill a low agriwlillral polenrial area. Unpublished Ph. D. thesis: University of Cape Town; 1985.

2. Erglund AL. ZlIllIlllOlIghl-pat/erns and symbolism. David Philip, Cape Town; 1976 
3. Kuper A. Willes for caule: bridel health and marriage illsOl/them Aji'ica. Routledge \& Kegan Paul, London; 1982.

4. Hammond-Tooke D. Rituals and medicines: indigenous healing in South Africa. Johannesburg; 1989.

5. Lee SG. Spirit possession among the Zulu. In: Beattie, Leton M, editors Spirit medillmship and sociery in Africa. Routledge \& Kegan Paul, London; 1969.

6. Gericke N. Useful guidelines and tips for fieldworkers. The Indigenols Plo1l Use Newsletter. 1994;2(4):11.
7. Kiernan JP. Prophet and preacher: an essential partnership in the world of Zion. Man (NS). 1976;11(3):356-366.

8. Raum OF. The social functions of avoidallces and taboos among the Zulu. Berlin: Walter de Gruyter; 1973.

9. Ngubane H. Body and mind ill ZIIII/medicine. London: Academic Pres; 1977. 